\title{
ELITES LOCAIS, ENFERMIDADES E TERAPÊUTICA CASEIRA EM UMA FREGUESIA DO BRASIL MERIDIONAL: O CASO DO TRATAMENTO DE MARIA FERREIRA DE OLIVEIRA - FREGUESIA DE MORRETES, PROVÍNCIA DE SÃO PAULO (1839-1840)
}

\author{
André Luiz Moscaleski Cavazzani ${ }^{1}$ \\ Sandro Aramis Richter Gomes ${ }^{2}$
}

\section{Introdução}

Neste artigo é empreendida uma análise a respeito da terapêutica empregada para aplacar as enfermidades de Maria Ferreira de Oliveira (1787-1840), nos anos de 1839 e 1840. O tratamento dessas doenças foi executado pelo comerciante de origem portuguesa Antônio Vieira dos Santos (1784-1854), marido de Maria Ferreira. Nessa época, o casal residia na freguesia de Morretes, que pertencia à jurisdição da vila litorânea de Antonina, situada no litoral sul da Província de São Paulo.

Antônio Vieira dos Santos nasceu na cidade portuguesa do Porto. Transferiu-se para o Brasil em 1797. Residiu, inicialmente, na cidade do Rio de Janeiro. Migrou para a vila de Paranaguá, localizada no litoral do atual Estado do Paraná, em 1798. Casou-se com Maria Ferreira de Oliveira em 1804. Após atuar como comerciante varejista em Paranaguá, ele se estabeleceu na então freguesia de Morretes em 1814, onde exerceu a ocupação de negociante de erva-mate, e ocupou cargos públicos, tais como o cargo de Juiz de Paz ${ }^{3}$.

Cumpre salientar, em síntese, que o estudo dos textos memorialísticos de Antônio Vieira dos Santos apresenta evidências acerca da natureza do tratamento caseiro elaborado por membros da elite social de uma freguesia do litoral sul da Província de São Paulo. Tratava-se de um contexto no qual a carência de médicos era aspecto peculiar à região.

Assim, os textos de Vieira dos Santos comportam indícios de que o tratamento de enfermidades, naquela freguesia, era caracterizado tanto pelo contato ocasional com médicos quanto pelo emprego rotineiro de recomendações fornecidas por curandeiros, boticários, escravos e manuais de medicina popular. Nesse sentido, compete demonstrar que um tratamento caseiro, no mencionado contexto, revestia-se

\footnotetext{
${ }^{1}$ Doutor em História Social pela Universidade de São Paulo. Realizou estágio pós-doutoral junto ao Departamento de História da Universidade Federal do Paraná entre 2014 e 2015. Docente e Coordenador do Curso de Graduação em História do Centro Universitário Internacional de Curitiba UNINTER. E-Mail: <andrexcava@gmail.com>.

2 Doutorando em História pela Universidade Federal do Paraná. Bolsista Capes. E-Mail: $<$ argomes8@gmail.com>.

${ }^{3}$ Concernente às atividades sociais de Vieira dos Santos na freguesia de Morretes, ver COSTA, Samuel Guimarães da. O último capitão-mor (1782-1857). Curitiba: Editora da UFPR, 1988.
} 
de um caráter eclético, visto que admitia a aplicação de sugestões advindas de distintas fontes - a medicina erudita e as artes populares de cura.

$* * *$

Cabe destacar que Maria Ferreira era filha do comerciante João Ferreira de Oliveira, que imigrou da Ilha do Pico, no Arquipélago dos Açores, para o Brasil em fins do século XVIII. Ao se estabelecer na freguesia de Morretes, ele atuou como comerciante. A família Ferreira de Oliveira pertencia à elite social dessa freguesia ${ }^{4}$. Assim, as informações analisadas ao longo deste artigo dizem respeito ao tratamento de saúde da integrante da elite social de uma pequena sociedade do Brasil Meridional $^{5}$.

Neste artigo, sustenta-se o argumento de que ausência de médicos impelia os habitantes de Morretes a ministrarem aos seus familiares enfermos uma terapêutica ensinada por manuais de medicina popular produzidos na Europa. Essas dificuldades, em suma, exigiam que os familiares da aludida enferma improvisassem formas de terapêutica. Nesse cenário de adversidades, a manutenção de correspondência epistolar com médicos era o recurso mais factível aos familiares de Maria Ferreira. Os membros da aludida parentela despenderam os recursos pecuniários para a contratação dos serviços de médicos, mas também requereram o auxílio de curandeiros, boticários e escravos que detinham o conhecimento sobre práticas terapêuticas caseiras.

$* * * *$

O presente artigo é desenvolvido em três etapas. Na primeira etapa, é elaborada uma análise acerca dos estudos sobre a história da saúde no Brasil oitocentista. Nesse quadro, compete evidenciar que a historiografia tem dedicado atenção para a natureza das políticas públicas na área sanitária $e$ as formas de atuação de curandeiros em sociedades provinciais. Cabe salientar que, presentemente, os estudos históricos têm avançado na investigação respeitante à eclosão de epidemias sanitárias $e$ às formas de intervenção de autoridades provinciais no curso dessas epidemias. Porém, permanece pouco desenvolvido o estudo sobre as características e implicações dos tratamentos de saúde caseiros em áreas provinciais do Império.

\footnotetext{
${ }^{4}$ Acerca da trajetória de membros dessa parentela, ver CAVAZZANI, André Luiz Moscaleski. Tendo o sol por testemunha: população portuguesa na Baía de Paranaguá (c. 1750-1830). Tese (Doutorado em História Social). Universidade de São Paulo. São Paulo, 2013.

${ }^{5}$ Em 1853, foi criada Província do Paraná. No ano seguinte, o presidente da província, Zacarias de Góes e Vasconcelos, produziu um relatório no qual é informado o contingente populacional dos municípios da nova província. A análise dessas informações permite evidenciar que, em meados do século XIX, a antiga freguesia de Morretes, que fora elevada à condição de Vila em 1841, possuía uma população inferior à população dos municípios de Antonina e Paranaguá. De acordo com o mencionado relatório, o contingente populacional do litoral paranaense, em 1854, estava distribuído do seguinte modo: Paranaguá - 6.533 habitantes; Antonina - 4.160 habitantes; Morretes - 3.709 habitantes; Guaratuba - 3.564 habitantes; Guaraqueçaba - 3.475 habitantes. VASCONCELOS, Zacarias de Góes e. Relatório do presidente da província do Paraná na abertura da Assembleia Legislativa Provincial em 15 de julho de 1854. Curitiba: Typographia de Cândido Martins Lopes, 1854, p. 14.
} 
$\mathrm{Na}$ segunda etapa do estudo, são analisados os aspectos do princípio do tratamento de Maria Ferreira. Nesse âmbito, é salientado que o marido da enferma, Vieira dos Santos, buscou a orientação de um médico para iniciar o tratamento das enfermidades de seu cônjuge. Contudo, a autoridade das recomendações médicas, no âmbito da família de Vieira dos Santos, não possuía precedência em relação às recomendações de indivíduos que atuavam como curandeiros na freguesia de Morretes. Antes, o responsável pelo tratamento de Maria Ferreira promoveu a junção de orientações fornecidas tanto por profissionais da Medicina quanto por curandeiros e leigos.

$\mathrm{Na}$ terceira etapa, salienta-se que o estabelecimento de contato da família Vieira dos Santos com um médico atuante na região do litoral do atual Estado do Paraná tornou-se menos frequente após o mês de abril de 1840. As tentativas do patriarca Antônio Vieira dos Santos de se comunicar por meio de missivas com aquele profissional não tinham sucesso.

Por conseguinte, demonstra-se que, nos meses seguintes, coube ao marido da enferma ministrar a ela um tratamento paliativo. Esse tratamento destinado apenas a aplacar momentaneamente os padecimentos físicos de Maria Ferreira. Dessa forma, cumpre asseverar que a análise da terapêutica aplicada no curso da enfermidade de Maria Ferreira evidencia que a obtenção de orientações médicas não impediu que o seu esposo buscasse os préstimos de curandeiros.

A fonte empregada para o desenvolvimento deste artigo é o Quadro da vida e morte de Maria Ferreira de Oliveira. Escrito por Antônio Vieira dos Santos, esse texto pertence ao volume de manuscritos memorialísticos que recebeu o título de Memórias dos sucessos mais notáveis acontecidos desde o ano de 1838, cuja redação foi encerrada em $1851^{6}$.

\section{Doenças, Políticas Sanitárias e Formação de Médicos na Historiografia do Brasil Oitocentista}

A historiografia brasileira, há tempos, tem dedicado atenção aos fatores do surgimento de surtos epidêmicos em províncias do Império e às formas de envolvimento de agentes estatais na formulação de medidas para previr ou minorar os efeitos desses surtos. Dessa forma, constata-se que vigora na historiografia uma inclinação para os estudos acerca do surgimento de epidemias em distintas áreas do Império e das ações deflagradas pelos governos provinciais para intervir nesse problema.

Em síntese, as investigações sobre o estado sanitário das províncias imperiais são marcadas pela propensão de evidenciar a ligação entre os surtos epidêmicos e as medidas administrativas empregadas para contê-los. Essa propensão é a característica

\footnotetext{
${ }^{6}$ Esse volume está sob a guarda do Círculo de Estudos Bandeirantes (Curitiba, Rua XV de Novembro, 1050). Nessa instituição está preservado outro volume de textos memorialísticos de Antônio Vieira dos Santos, a saber, o Breve resumo das memórias mais notáveis acontecidas de 1797 até 1827. Trata-se de uma fonte que é empregada neste artigo.
} 
dos estudos acerca, por exemplo, de províncias do Norte, como o Pará, e províncias do Sul do país, a exemplo do Paraná e Rio Grande do Sul ${ }^{7}$.

O estudo dos impactos das epidemias tem contribuído para o conhecimento tanto sobre as condições de vida da população quanto sobre as características demográficas das sociedades do Brasil oitocentista ${ }^{8}$. Nesse contexto, um avanço na investigação sobre as epidemias que grassaram no Brasil monárquico consiste no estudo a respeito das doenças em específicos grupos da sociedade, tais como os escravos ${ }^{9}$. Cabe destacar, também, que a análise sobre as enfermidades de escravos propicia o conhecimento sobre as formas de atuação de profissionais da Medicina em sociedades do interior do Império ${ }^{10}$.

De outra parte, compete salientar que a abordagem acerca de surtos epidêmicos possibilitou o conhecimento sobre as terapêuticas adotadas pela população em províncias como o Pará e o Rio Grande do Sul ${ }^{11}$. Presentemente, o estudo de trajetórias tem propiciado o conhecimento acerca das práticas populares de tratamento de doenças. Nesse quadro, esses estudos permitem a compreensão a respeito da autoridade concedida a indivíduos que desempenharam a função de curandeiros em províncias do Brasil oitocentista ${ }^{12}$. Por outro lado, tais análises também permitem o entendimento sobre o processo de esgotamento da autoridade conferida aos praticantes das artes populares de cura ${ }^{13}$.

Por fim, cumpre asseverar que o estudo sobre a formação de profissionais da medicina tem auferido atenção dos historiadores. Esse estudo não se limita ao caso

\footnotetext{
${ }^{7}$ Respeitante ao caso do Pará compete consultar, notadamente, os seguintes estudos: COSTA, Magda Nazaré Pereira da. Caridade e saúde públicas em tempo de epidemias (Belém, 1850-1890). Dissertação (Mestrado em História). Universidade Federal do Pará. Belém, 2006. Acerca dos estudos sobre doenças que se atém a sociedades do Sul do Brasil, ver: CRUZ, Gisela Thiel Della. As misérias da cidade: população, saúde e doença no Rio Grande no final do século XIX. Dissertação (Mestrado em História). Universidade Federal do Paraná. Curitiba, 1998; DOLINSKI, João Pedro. Espaços de cura, práticas médicas e epidemias: febre amarela e saúde pública na cidade de Paranaguá (18521878). Dissertação (Mestrado em História das Ciências e da Saúde). Fundação Casa de Oswaldo Cruz. Rio de Janeiro, 2013; SIQUEIRA, Márcia Andreatta Dalledone. Saúde e doença na província do Paraná (1853-1889). Tese (Doutorado em História). Universidade Federal do Paraná. Curitiba, 1989.

${ }^{8}$ MARCÍLIO, Maria Luiza. "Mortalidade e morbidade da cidade do Rio de Janeiro imperial". Revista de História, n. 127-128, ago./ dez. 1992 - jan./jul. 1993, p. 53-68.

9 Respeitante aos recentes estudos sobre doenças que dedicam atenção ao caso dos escravos, ver: BASTOS, Francisco; BELLIDO, Jaime, KODAMA, Kaori \& PIMENTA, Tânia. "Mortalidade escrava durante a primeira epidemia de cólera no Rio de Janeiro (1855-1856)". História, Ciências, SaúdeManguinhos, vol. 19, 2012, p. 59-79. LIMA, Carlos Alberto Medeiros. "Fronteira, cana e tráfico: escravidão, doenças e mortes em Capivari - SP, 1821-1869". História, Ciências, Saúde-Manguinhos, vol. 22, 2015, p. 899-919.

${ }^{10}$ Ver: BARBOSA, Keith Valéria de Oliveira. Escravidão, saúde e doenças nas plantations cafeeiras do Vale do Paraíba fluminense, Cantagalo (1815-1888). Dissertação (Mestrado em História das Ciências e da Saúde). Fundação Casa de Oswaldo Cruz. Rio de Janeiro, 2014.

${ }^{11}$ Concernente ao caso do Pará, ver: BELTRÃO, Jane Felipe. Cólera, o flagelo de Belém do Pará. Belém: Editora da UFPA, 2004. Acerca do caso do Rio Grande do Sul, ver: WITTER, Nikelen Acosta. Dizem que foi feitiço: as práticas de cura no sul do Brasil (1845 a 1880). Porto Alegre: EDIPUCRS, 2001.

${ }^{12}$ FARIAS, Rosilene Gomes. "Pai João, o curandeiro africano, e a medicina no Pernambuco imperial". História, Ciências, Saúde-Manguinhos, vol. 19, 2012, p. 215-231.

13 PIMENTA, Tânia. "Barbeiros, sangradores e curandeiros no Brasil (1808-28)". História, Ciências, Saúde-Manguinhos, vol. 5, n. 2, 1998, p. 349-374.
} 
da formação de médicos ${ }^{14}$. Antes, essa vertente de investigação também se inclina para a compreensão das características da formação dos cirurgiões desde a época colonial $^{15}$. Dessa maneira, tal linhagem de estudo é dedicada a destacar as medidas executadas por autoridades dos períodos colonial e imperial para minorar o problema da carência de profissionais da medicina no Brasil.

Contudo, remanesce pouco avançado, na historiografia, o estudo acerca das dificuldades enfrentadas pela população das províncias para terem acesso a médicos. Por consequência, permanece não desenvolvida a investigação sobre a natureza das alternativas que tal população formulava para contornar o problema da impossibilidade de obter de modo contínuo o auxílio de médicos. Desse modo, as características e consequências dessas alternativas são temas que não integram a contemporânea agenda de pesquisa da historiografia brasileira.

Nesse âmbito, os textos memorialísticos de Antônio Vieira dos Santos apresentamse como subsídios para o fornecimento de informações acerca do cotidiano do tratamento de doenças em sociedades interioranas do Brasil Meridional, no contexto das quatro primeiras décadas do século XIX. Essas informações, por sua vez, evidenciam que na região na qual a família desse comerciante português residia não havia a preeminência do saber médico sobre o saber dos indivíduos que dominaram as artes populares de cura.

Em síntese, o caso de Maria Ferreira de Oliveira evidencia que, em uma sociedade do interior de província do Império, a legitimidade conferida por membros de elites locais às artes populares de cura, a despeito do fato de esses membros terem condições econômicas de requisitar os serviços de médicos.

\section{A Busca pelo Auxílio Médico e as Dificuldades do Tratamento: o Início da Enfermidade de Maria Ferreira de Oliveira}

Neste estágio da análise, cabe evidenciar que a busca da orientação médica para o tratamento das enfermidades de Maria Ferreira foi realizada pelo seu marido, Antônio Vieira dos Santos. Contudo, a dificuldade para contatar-se com o médico levou o referido comerciante a recorrer a uma forma caseira de tratamento. Trata-se, portanto, de demonstrar que, no contexto do litoral sul da Província de São Paulo, nas primeiras décadas do século $\mathrm{XIX}$, os membros das elites locais requisitavam de forma contínua a orientação de médicos.

Entretanto, essa requisição não impedia que tais membros buscassem o auxílio de indivíduos que dominavam as artes populares de cura. Em um ambiente marcado pela carência de assistência médica, os conhecimentos oriundos da medicina oficial eram empregados em conjunto com as sugestões de curandeiros, boticários e leigos. Nesse âmbito, havia integrantes de elites locais que, como Maria Ferreira e seu

${ }^{14}$ EDLER, Flávio Coelho. Ensino e profissão médica na Corte de Pedro II. Santo André: Editora da UFABC, 2014.

${ }^{15}$ Ver: FIGUEIREDO, Betânia Gonçalves. "Barbeiros e cirurgiões: a atuação dos práticos ao longo do século XIX". História, Ciências, Saúde-Manguinhos, vol. 6, n. 2, 1999, p. 277-291. SANTOS FILHO, Lycurgo. História geral da medicina brasileira - Vol. 1. São Paulo: EDUSP, 1991. 
esposo, aproximavam-se de indivíduos pertencentes a posições inferiores na hierarquia social em busca de sugestões de tratamento de saúde.

Compete, inicialmente, destacar a maneira pela qual Vieira dos Santos buscou apresentar as causas dos padecimentos físicos de sua esposa. No princípio do Quadro da vida e morte, ele salientou:

Tendo emfim, em 1837, completado a idade de 50 annos, em cujo periodo sempre costuma fazer crise a natureza, na cessação de fluxo menstrual $p^{r}$ cuja cauza experimentara no $\mathrm{m}^{\text {mo }}$ anno e no de 1838 grandes variedades no corrimento do dito fluxo não apparecendo este com abundancia $e$ regularidade; mas sim em pequena quantidade e em dias interpolados ora antecipandose do tempo costumado ora retardandose alguns mezes acompanhados quazi sempre com $m^{\text {to }}$ fastio; encomodos e dores; ventozidades, adstrição do ventre, adjunto a ter sofrido alguns desgostos: dissabores $e$ pezáres no governo doméstico de sua vida, e varios sentimentos cauzados $p^{\text {los }}$ falescimentos de $m^{\text {tas }}$ pessoas q' the erão mais cháras; tudo unido a hum genio frenetico; motivos bem sufficientes que pouco a pouco forão minando a sua saude $e$ donde se originou a perigoza e gravissima enfermidade que pondo termo final á sua existencia a levou té a sepultura em 13 de $9^{\text {bro }}$ de $1840 .{ }^{16}$

Vieira dos Santos afirmou, portanto, que foram três as principais causas do aparecimento das enfermidades de sua esposa. Uma das causas era a interrupção do ciclo menstrual, que teria ocorrido quando Maria Ferreira estava na faixa etária dos cinquenta anos. Dessa maneira, Vieira dos Santos argumentou que o adoecimento do cônjuge seria decorrente de uma mudança fisiológica. Outra causa das enfermidades seria o abatimento decorrente das mortes de pessoas de seu círculo social. Por fim, as características da personalidade da enferma também teriam contribuído para o surgimento dos mencionados padecimentos.

Em suma, Vieira dos Santos era defensor do argumento segundo o qual a entrada em uma nova etapa do ciclo vital, marcada pela cessação da menstruação, e fatores como as aflições cotidianas eram capazes debilitar a saúde feminina. No entendimento daquele comerciante, a conjugação desses fatores propiciava o aparecimento de doenças crônicas.

Em 1839, Maria Ferreira enfrentava o problema de fluxo menstrual intenso. Tal problema se agravou ao longo daquele ano. Diante desse agravamento, Vieira dos Santos entrou em contato, por meio de carta, com o médico Guilherme Wylie, que residia na vila de Paranaguá. Esse município dista cerca de trinta quilômetros de Morretes. Wylie estava domiciliado em uma localidade que, no contexto da primeira metade do século XIX, já detinha a maior população dentre os municípios do litoral

${ }^{16}$ SANTOS, Antônio Vieira dos. Memórias dos sucessos mais notáveis acontecidos desde o ano de 1838. [Manuscrito]. Morretes, s.d., p. 357. 
do atual Estado do Paraná. A relevância econômica dessa vila decorria, ainda, das atividades portuárias ali realizadas ${ }^{17}$.

Tratava-se de um contexto em que existiam apenas duas faculdades de Medicina no Brasil. Inauguradas em 1832, essas instituições estavam sediadas nas cidades do Rio de Janeiro e Salvador ${ }^{18}$. Tal situação, que ocasionava a carência de médicos nas províncias do Império, permitiu que Wylie tivesse os seus serviços demandados por habitantes de municípios próximos à vila de Paranaguá. Ao longo do século XIX, apenas um indivíduo nascido nesse município obteve a formação em Medicina. Após concluir a graduação, em 1873, no Rio de Janeiro, tal indivíduo retornou à cidade natal para clinicar ${ }^{19}$.

Nesse âmbito, compete asseverar que a comunicação por carta realizada entre Wylie e Vieira dos Santos em 1839 é uma evidência dos reveses que a população do Império, inclusive os membros de elites locais, encontrava para receber de forma rotineira o acompanhamento de médicos. Nessa oportunidade, Wylie não respondeu a missiva de Vieira dos Santos. A impossibilidade de contato repetido ou circunstancial com os médicos gerava uma situação na qual os familiares dos enfermos tinham de improvisar um tratamento. Contudo, esse tratamento improvisado era marcado por reveses.

Leia-se, portanto, a informação apresentada por Vieira dos Santos acerca das implicações nocivas do tratamento que ele formulou para o tratamento sua esposa. Na primeira missiva que enviara a Wylie, aquele comerciante português informou que já aplicava uma terapêutica para combater enfermidades de sua esposa. Naquele momento, o tratamento não tivera resultado positivo. Um dos aspectos desse tratamento era a realização de vomitórios. Vieira dos Santos, portanto, buscava tratar a enfermidade da esposa por meio do procedimento de limpeza estomacal:

Por cauza do continuado fastio pertendeose $p^{r}$ tanto mete-lha em curativo $p^{a}$ o q' escrevi a pra carta sobre este objecto consultando ao Medico da $V^{a}$ de Paran ${ }^{a}$ o $D^{\text {or Guilherme }}$ Wyle o qual como me não dese resposta; escrevi $s g^{d a} p^{10} m^{m o}$ mesmo theor pouco mais ou menos em fins de $8^{\text {bro }}$ ou principio de $9^{\text {bro }}$ dizendo-lhe que tinha receitado o vomitorio de puaia $e$ purgantes de ruibarbo e cremor e alguns cozimentos de gengibre erva doce e noz moscada clisteis: $e$ como com este methodo não declinava a melhoras receiteilhe $p^{a}$ beber todos os dias leites quentes de vacca em cujo uzo parece esteve todo o mez de $8^{\text {bro }}$ e $9^{\text {bro }}$ e era este quazi o unico alimento com q' se sustentava. O uzo dos leites the fizerão hum grandissimo damno enchendo estomago de flatos $e$ arrotos tirando mais a vontade de comer e $p^{r}$ consequencia

${ }^{17}$ WESTPHALEN, Cecília. Porto de Paranaguá: um sedutor. Curitiba: Secretaria Estadual da Cultura, 1998.

${ }^{18}$ EDLER, Flávio Coelho. Medicina no Brasil imperial: clima, parasitas e patologia tropical. Rio de Janeiro: Editora Fiocruz, 2011.

${ }^{19}$ HOERNER JÚNIOR, Valério. A vida do Dr. Leocádio José Correia. Curitiba: Vicentina, 1979. 
augmentandose cada ves mais a debelidade ficando com hum semblante tristonho e palido e cada ves mais desfigurado intentei neste caso mudar inteiram ${ }^{\text {te }}$ do methodo curativo, pasando a usar de remedios corroborantes e usar de manhã, das 11 horas do dia e a tarde beber $24 g^{r}$ de quina em vinho com outros cozimentos adequados e de ves em $q^{\text {do }}$ purgantes de ruibarbo e asim se foi entretendo té fim de Dezembro mas o corrimento não suspendia e o fastio cada ves mais de manr ${ }^{a}$ q' desde o dia 25 de Dezembro em diante se achava $m^{\text {to }}$ esmorecida e bastantem ${ }^{\text {te }}$ desanimada. ${ }^{20}$

Diante do malogro da tentativa de comunicar-se com Guilherme Wylie, Vieira dos Santos precisou elaborar rapidamente uma alternativa para abrandar os padecimentos do cônjuge. Compete salientar, portanto, que tal alternativa consistia em um método paliativo. $\mathrm{O}$ insucesso do tratamento paliativo e a impossibilidade de manter contato com o referido médico exigiu que o comerciante português formulasse um novo método para executar a terapêutica de enfermidade de Maria Ferreira. Essa terapêutica consistia na ingestão de remédios corroborantes, isto é, tonificantes destinados a possibilitar ao enfermo recobrar suas forças.

Conforme demonstrado neste artigo, um dos principais corroborantes utilizados por Maria Ferreira era um planta denominada de ruibarbo, comumente empregada para atenuar distúrbios gástricos ${ }^{21}$. De fato, Vieira dos Santos asseverou que a principal enfermidade de sua esposa era gastroenterite ${ }^{22}$.

Todavia, a nova terapêutica utilizada por Vieira dos Santos não teve resultados positivos. Durante as duas primeiras semanas de janeiro de 1840, Maria Ferreira de permaneceu adoentada. No entanto, não houve substancial modificação na forma de tratamento de sua moléstia. As informações transcritas a seguir evidenciam as dificuldades do esposo da enferma, no contexto de uma pequena sociedade provincial, para providenciar um tratamento de saúde. De outra parte, essas informaçóes demonstram que diante dessas dificuldades restou ao comerciante Antônio Vieira dos Santos manter a terapêutica marcada pela ingestão de tônicos e realizar procedimentos de purificação estomacal. Dessa forma, Maria Ferreira continuou a ingerir ruibarbo. A esse respeito, o memorialista informou:

\section{Janeiro de 1840}

1. Quarta feira em todo este dia esteve a $m^{e r} m^{\text {to }}$ triste, e té com semblante bem desfigurado.

2. Quinta fra neste dia achavase $m^{\text {to }}$ doente $m^{\text {to }}$ prostrada $e$ abatida de forsas (mau agouro) dando-lhe a miudo esmorecimentos e ataques de flatulencias, ordenei-lhe dessem bebidas corroborantes como vinho estomachico, cozimentos de gengibre de erva doce, comidas nutrientes e emplastos de

\footnotetext{
${ }^{20}$ SANTOS, Memórias dos sucessos..., p. 359.

${ }^{21}$ GONSALVES, Paulo Eiró. Livro dos alimentos. São Paulo: MG Editores, 2002.

${ }^{22}$ SANTOS, Memórias dos sucessos..., p. 377.
} 
marmelada sobre o estomago e a $\mathrm{m}^{\text {ma }}$ continuação nos dias 3

e

5. Domingo esteve todo este dua novamente doente $m^{\text {to }}$ abatida de animo e prostrada de forsas.

6. Segunda $\mathrm{fr}^{a}$ neste dia esteve $d a \mathrm{~m}^{\text {ma }} \mathrm{man}^{a} \mathrm{~m}^{\text {to }}$ abatida prostrada de forsas e $m^{\text {to }}$ dezanimada e dando-lhe o flato $p^{r}$ varias veses.

7. Terça e 8 quarta ficou algum tanto mais airoza com o uzo das bebidas corroborantes.

9. Quinta fra de tarde apeteceo comer hum bocado de queijo $e$ ovos fritos de que lhe procedeo certa indisposição do estomago a man $^{a}$ de hua indigestão. ${ }^{23}$

Dessa forma, tais informações permitem demonstrar que o tratamento caseiro de Maria Ferreira foi também marcado pela utilização de creme de tártaro e de uma técnica de injeção de água no ânus denominada de clister. Trata-se de um procedimento destinado à limpeza intestinal. Por outro lado, compete destacar que o emprego do ruibarbo era recomendado em livros de medicina popular em circulação no Brasil oitocentista.

Uma das principais obras desse gênero de livro era o Manual prático de medicina curativa, escrito pelo médico francês Alphonse-Louis-Vincent Leroy (1742-1816). Vieira dos Santos possuía um exemplar dessa obra, em edição de $1825^{24}$. Enfim, esse manual considerava o ruibarbo como uma eficaz substância purgativa ${ }^{25}$. Leroy era, pois, um autor cuja obra médica não fora isentada de críticas por outros autores de

${ }^{23}$ SANTOS, Memórias dos sucessos..., p. 360-361.

${ }^{24}$ SANTOS, Antônio Vieira dos. Breve resumo das memórias mais notáveis acontecidas de 1797 até 1827. [Manuscrito]. Morretes, s.r., p. 252. Para demonstrar o argumento segundo o qual os conhecimentos adquiridos no Manual de Leroy eram empregados por Vieira dos Santos, compete salientar que ele empregou tais conhecimentos no tratamento de suas próprias enfermidades. Em 1850, ele realizou o uso de um purgante cuja confecção era ensinada no mencionado manual. A informação transcrita a seguir não demonstra apenas a importância do citado manual no tratamento das enfermidades de Vieira dos Santos. Ela também evidencia que um curandeiro que auxiliou o tratamento de Maria Ferreira também tinha os seus préstimos requisitados por Vieira dos Santos. Nesse sentido, a informação apresentada na sequência demonstra que, após uma década do falecimento de Maria Ferreira, o curandeiro Julião ainda tinha os seus serviços requisitados na família de Vieira dos Santos. Trata-se, portanto, de uma evidência acerca da reiteração da dependência dos habitantes de pequenas sociedades provinciais para com os conhecimentos dos curandeiros. Leia-se, pois, a seguinte passagem do texto memorialístico de Vieira dos Santos: "Em 21 [de março de 1850] Quinta feira voltei $\mathrm{p}^{\mathrm{a}}$ caza por estar com o pé $\mathrm{m}^{\text {to }}$ inflamado com a impigem onde estive recluzo té o dia 22 tomando hum ou dois purgantes de Manna e Jalapa. Em 23 Segunda fra principiei a tomar purgantes de la Roy, em 25 botei póz dejounnes com o que se augmentou a inflamação. De noite se botou outro unguento ensinado por Julião té o dia 30. Em Dom ${ }^{\circ}$ 24, Segunda 25 e Terça 26 tomei o la Roy. Em 27 Quarta purgante de Sal amargo. Em 28, 29 e 30 outros de la Roy principiouse com novo unguento de semente de algodão". SANTOS, Memórias dos sucessos..., p. 219. Nesse quadro, compete salientar que, após o falecimento de Maria Ferreira, Vieira dos Santos permaneceu interessado em adquirir manuais de medicina doméstica. Ele possuía em sua biblioteca, por exemplo, um exemplar da obra Medicina doméstica homeopática ou Guia de curar homeopaticamente (1849), de Thomas Cochrane. SANTOS, Memórias dos sucessos..., p. 313.

${ }^{25}$ LEROY. La Medicina curativa, o la purgación. Valência: Imprensa de Ildefonso Mompie, 1829. 
manuais populares. A principal crítica dirigida a esse médico residia na sua defesa da ampla utilização de purgantes em um tratamento curativo ${ }^{26}$.

De outra parte, o texto memorialístico de Vieira dos Santos evidencia que o médico Wylie apresentava recomendações que estavam presentes, ao menos desde o século XVIII, em tratados de medicina publicados na Europa. Nesses livros médicos, o ruibarbo era apresentado como uma substância adequada para o tratamento de moléstias estomacais e intestinais ${ }^{27}$.

O tratamento ministrado por Vieira dos Santos à sua esposa consistia na ingestão de substâncias purgativas e fortificantes como recurso para mitigar os incômodos decorrentes do agravamento da enfermidade. Esse tratamento não sofreu expressivas alterações ao longo do ano de 1840. Contudo, Vieira dos Santos permaneceu inclinado a buscar o auxílio tanto do médico Wylie quanto de curandeiros. Em janeiro do mencionado ano, o marido de Maria Ferreira recebeu o auxílio de Luciana, escrava de Modesto Gonçalves Cordeiro, o qual detinha a patente de Capitão de Milícias e atuava como negociante de erva-mate em Morretes. Tratava-se, portanto, de indivíduo que pertencia ao mesmo grupo profissional de Antônio Vieira dos Santos.

De acordo com Vieira dos Santos, os remédios preparados por Luciana para Maria Ferreira tinham a finalidade de interromper o corrimento vaginal. No dia 15 de janeiro de 1840, "[Ferreira] principiara neste dia a beber huns remedios $\mathrm{p}^{\mathrm{a}}$ a suspensão de corrimentos feitos $\mathrm{p}^{\mathrm{la}}$ Luciana mulata do $\mathrm{Cap}^{\mathrm{m}}$ Modesto. Toda a tarde té perto das 9 horas da noite esteve bem incommodada com a dor de tudo. De $n$. tomou clisteis purgativos" 28 .

O tratamento caseiro das doenças de Maria Ferreira era desenvolvido de forma pouco disciplinada. Nesse contexto, a enferma possuía a prerrogativa de escolher o momento em que realizaria ou interromperia o uso dos remédios. A esse respeito,

${ }^{26}$ Alphonse Leroy angariara notoriedade pela produção de um purgante. Dentre os críticos desse purgante estava Pedro Luís Napoleão Chernoviz (1818-1881), polonês que se radicou no Brasil e escreveu obras de medicina popular. Crítico do consumo indiscriminado de purgantes, Chernoviz apresentou as seguintes considerações sobre o purgante cuja preparação fora ensinada nos manuais de Leroy: "Os purgantes e, particularmente, os mais enérgicos, os drásticos, são para os charlatães uma rica mina de que eles não cessão de explorar. [...] O purgante Leroy, de que devemos dizer aqui algumas palavras, tem também por base substâncias drásticas. [...] Os avisos das pessoas esclarecidas, e os conselhos dos mais sábios médicos não podem impedir o povo de recorrer a estas preparações incendiárias, e o purgante Leroy não cessa de fazer vítimas". CHERNOVIZ, Pedro Luís Napoleão. Diccionario de Medicina Popular. Volume Terceiro. Rio de Janeiro: Eduardo \& Henrique Laemmert, 1851, p. 310-311. Grifo no original.

${ }^{27}$ Na obra Materia Medica Physico-Historico-Mechanica (1735), escrita pelo português Jacob de Castro Sarmento (1691-1762), encontra-se a defesa da utilização de ruibarbo. Trata-se, pois, de uma defesa realizada por médico que pertencia ao Real Colégio dos Médicos de Londres. Conforme Sarmento, o ruibarbo "Tomado em poucos graons, he a melhor medicina alterativa, e corroborante, nas relaxaçoens, e debilidades das fibras do Estomago, e Intestinos; e na mesma dose, mastigado os mais do dias, com a continuagem do tempo, tem felizmente curado Achaques Chronicos, que não cederam a outros Remedios; o que por experiencia observei em muitos, e em mim mesmo, livrandome das inveteradas colicas nervosas que padecia huma grande parte da minha vida, por meyo do repetido uso do Ruibarbo mastigado, que continuei pelo tempo de quatro para cinco anos". SARMENTO, Jacob de Castro. Materia Medica Physico-Historico-Mecanica. Reyno Mineral. Londres: Caza de Guilherme Strahan, 1758, p. 502-503.

${ }^{28}$ SANTOS, Memórias dos sucessos..., p. 361. 
atente-se ao seguinte excerto do Quadro da vida e morte de Maria Ferreira de Oliveira, o qual diz respeito a de episódios ocorridos nos dias 26 e 27 de janeiro de 1840:

Domingo neste dia não quis tomar nenhuns remedios e pasou melhor queixandose do corpo estar tremendo com debelidade, mas de noite pasou bem. Segunda não tomou nenhuns remedios, esteve neste dia bem airoza com bem poucos arrotos e quazi sem nenhua dor de estomago, nem ventre. N.B. = dia 28, 29, 30 e 31 não se fes diario delles mas parece ter sido o mmo methodo curativo. ${ }^{29}$

Dessa forma, ocasionais melhoras no estado de saúde levavam Maria Ferreira a recusar prosseguir no consumo dos remédios prescritos tanto por Vieira dos Santos quanto pela escrava Luciana. As informações presentes no excerto supracitado, portanto, consistem em indícios do caráter pouco regrado do tratamento de saúde caseiro ao qual Maria Ferreira fora submetida. Nesse contexto, os familiares da enferma não possuíam condições de auxiliar o doente senão por meio da recomendação do uso de purgativos.

Em fevereiro de 1840, Vieira dos Santos tornou a enviar uma carta para o médico Guilherme Wylie. Nessa ocasião, conseguiu obter uma resposta desse profissional. Em resumo, constata-se que o tratamento recomendado por esse indivíduo consistia no consumo de fortificantes. Por outro lado, as informações transcritas a seguir evidenciam que Vieira dos Santos teria obtido orientações de outro médico, referido no texto memorialístico apenas como Dr. Gregório. A orientação desse indivíduo era para que Vieira dos Santos realizasse a aplicação de injeções (ou seringatórios) em Maria Ferreira.

Nessa época, persistia no Brasil a carência de médicos tanto nas mais populosas cidades do Império quanto em áreas do interior das províncias. O contingente de graduados pelas faculdades de Medicina do Rio de Janeiro e de Salvador era insuficiente para suprir essa carência. Tal situação impelia dos habitantes do Império, especialmente nas áreas rurais, a agirem frequentemente como médicos práticos. Em virtude da carência de médicos em áreas do interior das províncias, os fazendeiros atuavam ocasionalmente como médicos práticos ${ }^{30}$.

A precariedade da assistência médica tornava sobremodo necessária a improvisação de terapêuticas caseiras. Por conseguinte, os manuais de medicina doméstica eram largamente utilizados pelos cidadãos do Império. Essa ampla utilização dos manuais de medicina no Brasil perdurou durante os anos finais do século XIX. Em suma, tais manuais propiciaram a difusão de conhecimentos da medicina erudita em regiões marcadas pela referida precariedade ${ }^{31}$.

\footnotetext{
${ }^{29}$ SANTOS, Memórias dos sucessos..., p. 362.

${ }^{30}$ Ver COSTA, Emília Viotti da. Da senzala à colônia. São Paulo: Editora da UNESP, 1998.

${ }^{31}$ Ver GUIMARÃES, Maria Regina Cotrim. Civilizando as artes de curar: Chernoviz e os manuais de medicina popular no Império. Dissertação (Mestrado em História das Ciências e da Saúde). Fundação Casa de Oswaldo Cruz. Rio de Janeiro, 2003.
} 
Em síntese, as recomendações captadas em manuais de medicina popular e entre habitantes da freguesia de Morretes, tais como a escrava Luciana, eram encaradas por Vieira dos Santos como sumamente operacionais. Assim, o marido de Maria Ferreira não ansiava apenas pela orientação dos profissionais formados no saber da medicina erudita. A esse respeito, compete evidenciar que Vieira dos Santos procurou insistentemente manter contato com Guilherme Wylie:

Desde o $1^{\circ}$ dia té 27 [de fevereiro de 1840] se não fes diario dos remedios q' tomou e nem das alteraçõens que teve nos seus padecimentos por se julgar ter regulado ora com declinaçõens de melhoras e ora com repetiçõens de dores do ventre, cadeiras; ventosidades e cardialgia. Em 8 deste mez escrevi ao Dr. Guilherme Wylie Medico da $V^{a}$ de Paranagua pedindo-lhe receituarios $p^{a}$ curativo de sua molestia; o qual me deu resposta no dia 20 mandando q' ella tomase banhos salibrozos emborcativos d'agoá fria e tomar remedios tonicos como os póz de Gregorio e seringatórios adstringentes. Quarta principiou a tomar huas pilulas q' o Medico mandou, e tambem o poz tonicos do Dr. Gregorio e tambem os seringatorios com os quaes continuou no dia 5 quinta. Quinta principiou neste dia a tomar segunda ves as pilulas q' o Medico tinha mandado e os poz do Dr. Gregorio e continuou a tomar os $m^{\text {mos }}$ remedios nos dias 13 e 14. Na noite deste dia the sobreveio hua nova dor nas verilhas; e repetição na do lado do ventre porem não durou $m^{\text {to }}$ tempo. ${ }^{32}$

As informações apresentadas por Vieira dos Santos permitem constatar que, em uma sociedade carente de médicos, restava aos familiares dos enfermos manterem contato, por meio de cartas, com médicos de municípios vizinhos. Nesse quadro, havia um duplo entrave para os moradores da freguesia de Morretes. Um entrave era conseguir manter uma comunicação regular com os médicos. O segundo entrave era obter os medicamentos e realizar disciplinadamente as recomendações médicas. Cabe destacar, pois, que em março de 1840 Vieira dos Santos voltou a enviar uma missiva para Wilye. Nela, relatava as dificuldades que estava a vivenciar para desenvolver adequadamente o tratamento prescrito pelo médico:

[31 de março de 1840] Terça de manhã pasou melhor mas de tarde lhe repetio a dor periódica nas cadeiras e no lado do ventre na forma de costume que só $p^{\text {las }} 9$ ou 10 horas da noite he que tinha algum socego e quando podia dormir. Em 28 de Março escrevi a $4^{a}$ carta ao Dr. Guilherme Wylie em que lhe relatava os inconvenientes de se não poder ter posto em

${ }^{32}$ SANTOS, Memórias dos sucessos..., p. 363-364. 
pratica os remedios q' receituara; $e$ o estado em q' se achava. $^{33}$

Em virtude do insucesso do tratamento realizado por meio de correspondência epistolar, Vieira dos Santos e Maria Ferreira viajaram até a vila de Paranaguá com a finalidade de consultar com Guilherme Wylie. Nessa época, o problema do corrimento vaginal era a moléstia que motivara a busca pela orientação de Wylie. Na mencionada viagem, Vieira dos Santos e Maria Ferreira estavam acompanhados do filho primogênito, Antônio Júnior, então na idade de trinta e cinco anos.

Desse modo, a consulta de Maria Ferreira com Wylie foi uma ocasião adequada para que Antônio Júnior também pudesse dispor dos serviços do médico. Nessa ocasião, o primogênito realizou um procedimento cirúrgico com Wylie. A consulta ao médico, portanto, consistiu em um episódio que mobilizou diferentes membros da família de Vieira dos Santos. Atente-se, portanto, aos seguintes episódios ocorridos no mês de abril de 1840:

Quarta de tarde foi atacada fortemente com as dores costumadas nas cadeiras e ventre botarão-se-lhe emplastos estomachicos e antes hystericos; ralhei com ella sobre não querer tomar os remedios que se lhe applicavão chorou muito maldizendose de sua vida e dezanimada que havia de morrer. N.B. = desta maneira mais ou menos pasou desde o dia 2 ate $10 \mathrm{em}$ q' rezolveu hir ter a festa da Pascoa e levar a ella a Paranagua $p^{a}$ mostrar ao medico a fim de lhe applicar os remedios appropriados. Sabado de manhã cedo sahi dos Morretes com $m^{a}$ familia e de tarde chegamos a $V^{a}$ de Paran ${ }^{a}$ N.B. = desde $12 \mathrm{dom}^{\circ}$ ate 16 pasou em todos estes optimamente, $m^{\text {to }}$ esperta, paçeando e comendo bem, alegre e vissoza, parece que neste mesmo dia foi chamado o medico o Dr. Guilherme Wylie e na Seg ${ }^{d a} 13$ em diante principiou a tomar suas pilulas q' elle fes $p^{a}$ parar o corrimento de fluor album mas sem effeito que mudou $p^{a}$ huns por differentes q' tambem não fizerão obra e $\mathrm{m}^{\text {mo }}$ porque repugnava toma-los. [Em 21 de abril] de manhã o medico veio abrir o sedenho em meu filho Antônio. ${ }^{34}$

Na vila de Paranaguá, Maria Ferreira procurou pelo auxílio de uma curandeira. Segundo Vieira dos Santos, a curandeira ministrou a Maria Ferreira conhecimentos sobre a preparação de remédios: "[Em 16 de abril de 1840] Quinta fra Santa de noite $\mathrm{M}^{\mathrm{a}}$ foi a Igra $^{\mathrm{a}}$ Matriz ver o sermão da Paixão e depois pacear $\mathrm{p}^{\text {las }}$ ruas te foi a caza de hua $\mathrm{m}^{\text {er }}$ curandeira $\mathrm{p}^{\mathrm{a}}$ lhe ensinar alguns remédios" 35 .

\footnotetext{
${ }^{33}$ SANTOS, Memórias dos sucessos..., p. 365.

${ }^{34}$ SANTOS, Memórias dos sucessos..., p. 366.

${ }^{35}$ SANTOS, Memórias dos sucessos..., p. 366.
} 
O saber médico, nesse contexto, possuía o reconhecimento de integrantes da elite social da freguesia de Morretes. Contudo, esses integrantes não se eximiam de buscar auxílio de curandeiros. Por conseguinte, eram executados, naquela sociedade, tratamentos de saúde distinguidos pelo ecletismo, visto que consistiam na junção de conhecimentos oriundos de duas fontes diferentes - a medicina oficial $e$ as artes populares de cura.

Conforme demonstrado neste artigo, as recomendações médicas orientaram, inicialmente, a rotina de tratamento de Maria Ferreira. Todavia, a falta de contato frequente com o médico criou uma situação na qual as recomendações de boticários e curandeiros passaram a influir de forma mais decisiva na terapêutica da enferma.

Por outro lado, a consulta de Maria Ferreira com o médico Wylie assumiu o caráter de acontecimento familiar. Tal caráter era, pois, uma consequência da ausência de médicos na sociedade em que a família da enferma estava enraizada. Para aplacar os incômodos de Maria Ferreira, Wylie receitou a ela a ingestão de pílulas de valeriana, um sedativo fitoterápico.

Após a consulta, o tratamento das enfermidades de Maria Ferreira tornou-se mais regrado. Houve, pois, a estrita definição de horários para a ingestão de medicamentos $e$ a realização de procedimentos como os clisteres. Porém, as recomendações médicas foram infrutíferas. Dessa forma, sintomas como as febres intermitentes continuaram a fazer parte dos padecimentos físicos de Maria Ferreira. A primeira semana do mês de maio de 1840 foi o período no qual o tratamento de Maria Ferreira assumiu um caráter mais regrado:

30 [de abril de 1840]. A 1 hora da tarde tomou as 2 pilulas de valeriana. A $1^{1 / 2} \mathrm{hr}$. bebeo caldo de galinha = as $2 \mathrm{hr}$. e 45 min. tomou 2 pilulas de sulphato e limonada de esp ${ }^{\circ}$ de vitríolo; as $4 \mathrm{hr}$. outras 2 pilulas bem como as 5 horas as 6 horas e as 7 horas depois clysteis e banhos; as 8 horas e meia ceou e perto das $9 \mathrm{hr}$. 2 pilulas de valeriana. De noite dormio sofrivelmente sem q' houvesse maior novidade.

1 [de maio]. Sesta, $p^{\text {las }} 6^{1 / 2}$ horas da manhã tomou 2 pilulas de valeriana bem como outras 2 de resto as $7^{1 / 2}$. Neste dia não the vierão os frios, nem as febres e de noite pouco dormio com a dor do vesicatorio chegou a canoa dos Morretes que nos vinha buscar.

2. Sabado de manhã tomou as 2 pilulas de valeriana pelas 9 horas 1 de sulphato de quinina bem como outras $p^{\text {las }} 10$ horas outra $p^{\text {las }} 11$ e outra $p^{\text {lo }}$ meio dia, depois jantou e $p^{r} 1$ hora da tarde tomou 2 pilulas de valeriana; e $p^{\text {las }} 3,4$, e 5 horas 1 de sulphato. Depois das 8 horas da noite 2 pilulas de valeriana e clysteis. Dormio soffrivelmente esta noite.

3. Domingo de manhã tomou 2 pilulas de valeriana não tomou as de sulphato ate a tarde $p^{r}$ não

ter mais, mas $p^{\text {las }} 4$ horas da tarde, 5, 6, 7 e ate 8 horas tomou 1 de cada ves; e depois das 8 as 2 de valeriana. A noite pasou soffrivelmente. 
4. Segunda $\mathrm{fr}^{a}$ de manhã nos embarcamos na $V^{a}$ de Paran $^{a}$ e chegamos aos Morretes $p^{\text {las }} 2$ horas

da tarde $p^{\text {las }} 8$ horas tomou as 2 pilulas de valeriana e $p^{\text {las }}$ 9 horas, 10, 11 e 12 hua de sulphato. ${ }^{36}$

Maria Ferreira não voltou a consultar com Guilherme Wylie. Os episódios referentes à enfermidade de Ferreira, conforme apresentados no Quadro da vida e morte, evidenciam que o tratamento a ela ministrado por Vieira dos Santos assumiu, a partir de maio de 1840, um aspecto meramente paliativo. Em síntese, o marido da enferma tinha apenas condições de fornecer remédios que minoravam circunstancialmente os sintomas, tais como as dores estomacais e o corrimento vaginal. Em virtude da permanência dos padecimentos de sua esposa, Vieira dos Santos contratou os serviços de um curandeiro e de um boticário.

No momento em que solicitou esses serviços, Vieira dos Santos ministrava à sua esposa um tratamento marcado pela ingestão de fitoterápicos. Um dos fitoterápicos empregados nesse tratamento era a planta denominada de Goma Arábica. Cabe destacar, pois, que Vieira dos Santos estava a empregar medicação secularmente recomendada em obras que circulavam na Europa. A Goma-arábica, por exemplo, consta no livro Erário Mineral (1735), do cirurgião português Luís Gomes Ferreira (1686-1764), como medicamento eficaz para revigorar os movimentos dos braços e pernas $^{37}$.

Nesse contexto, o tratamento de Maria Ferreira consistia em ingerir remédios que promoviam episódicos alívios em suas dores crônicas. Por outro lado, ela também utilizava um medicamento de uso externo - um emplastro posicionado sobre o abdômen, como forma de mitigar os incômodos decorrentes das dores estomacais. Vieira dos Santos detalhou o modo pelo qual a Goma-arábica foi empregada no tratamento de Maria Ferreira. A utilização dessa planta no tratamento da enferma fora realizada sob a orientação da esposa de Antônio Luiz Pereira:

[25 de maio de 1840] Segunda e 26 terça esteve nestes dias bem atacada com fortes dores de dentes e só de ves em quando lhe davão algum peq ${ }^{\text {no }}$ intervallo de alivio e na terça principiou a tomar o remedio feito de Genebra com gomarabia ensinado pella mulher de Antônio Luiz Pereira. Nos dias 27, 28, 29, 30 e 31 teve diariamente tanto de dia como de noite as dores de dentes. ${ }^{38}$

Assim, cerca de um mês após consultar o médico Wylie, Maria Ferreira estava a empregar em seu tratamento as recomendações de uma mulher que dominava um saber popular de cura. O excerto supracitado evidencia, pois, que uma terapêutica caseira, na freguesia de Morretes, era marcada pela admissão de recomendações de

\footnotetext{
${ }^{36}$ SANTOS, Memórias dos sucessos..., p. 370-371.

${ }^{37}$ FERREIRA, Luís Gomes. Erário mineral. Organização de Júnia Ferreira Furtado. Rio de Janeiro: Editora da Fiocruz, 2002 [1735], p. 560.

${ }^{38}$ SANTOS, Memórias dos sucessos..., p. 373.
} 
leigos que possuíam informações sobre o preparo e utilização de medicamentos caseiros.

Em síntese, os textos memorialísticos de Vieira dos Santos comportam indícios de que um tratamento de saúde, na referida freguesia, era caracterizado não somente pelo acatamento das recomendações de médicos e curandeiros. Antes, eram também admitidas as sugestões de leigos que pertenciam ao círculo de relações sociais dos familiares dos enfermos. O excerto supracitado evidencia, pois, que havia habitantes da mencionada freguesia que aglutinavam, em seus tratamentos de saúde, os saberes oriundos da medicina popular e da medicina erudita.

Em ambientes sociais tais como a freguesia de Morretes, o saber popular era mais acessível às famílias dos enfermos. Havia proximidade entre os indivíduos que produziam e os que consumiam remédios caseiros. A respeito da relação entre saber médico erudito e saber popular na história do Brasil, Flávio Edler destacou que os médicos profissionais se empenhavam em conter o crescimento da influência das artes de cura popular. No entanto, a população não se eximia de promover a coexistência entre ambos os saberes: "Se em ampla variedade de aspectos o saber erudito e o popular eram indissociáveis na experiência de distintos estratos sociais, os representantes da arte oficial lutavam ferrenhamente contra os que praticavam as curas na informalidade" ${ }^{39}$.

Nesse sentido, compete demonstrar, no estágio seguinte deste artigo, que a demanda pelos serviços de indivíduos que praticavam as artes populares da cura foi o derradeiro recurso empregado na terapêutica de Maria Ferreira. A comunicação por carta de Vieira dos Santos com Guilherme Wylie não tinha resultado, pois o médico, na maior parte dos casos, não respondia as missivas.

Por conseguinte, coube àquele comerciante recorrer aos préstimos de indivíduos com os quais possuía maior proximidade, visto que habitavam a freguesia de Morretes. Em síntese, as informações referentes ao tratamento de Maria Ferreira permitem sustentar a afirmação segundo a qual, no extremo sul da Província de São Paulo, não eram somente os curandeiros e boticários que estavam investidos da competência de preparar remédios. Antes, indivíduos que exerciam outras ocupações profissionais também praticavam as artes populares de cura. Na freguesia de Morretes, nos anos 1840, um alfaiate também se dedicava a esse expediente, conforme relatado no próximo item do artigo.

Nesse quadro, as informações analisadas na seção seguinte deste estudo evidenciam que a carência de médicos e a solicitação do auxílio de indivíduos que exerciam as artes de cura popular eram aspectos inerentes a uma pequena sociedade do litoral sul da Província de São Paulo. Ao mesmo tempo, reúnem-se informações para corroborar o argumento de que a terapêutica caseira era a principal forma de tratamento de saúde naquela localidade.

${ }^{39}$ EDLER, Flávio Coelho. Boticas e pharmacias: uma história ilustrada da farmácia no Brasil. São Paulo: Casa da Palavra, 2006, p. 18. 


\section{Boticários, Curandeiros e Cuidados Paliativos: os Últimos Meses do Tratamento de Maria Ferreira de Oliveira}

A partir do mês de junho de 1840, Maria Ferreira passou a receber mais assiduamente os préstimos de curandeiros e boticários. De junho a novembro do mencionado ano, o tratamento de suas enfermidades era marcado tanto pela utilização dos remédios preparados por curandeiros e boticários quanto pela execução de procedimentos como a limpeza intestinal por meio do clister. A realização de vomitórios também permaneceu integrada ao tratamento da enferma.

Dessa forma, a limpeza intestinal e estomacal era a técnica utilizada de forma rotineira na terapêutica da moléstia de Maria Ferreira. Ao mesmo tempo, compete salientar que, no segundo semestre de 1840, a enferma não voltou a Paranaguá para consultar com Guilherme Wylie. Nesse contexto, as cartas enviadas por Vieira dos Santos a esse médico não eram respondidas.

Esses reveses para a obtenção de novas orientações médicas impeliu Vieira dos Santos a acatar as sugestões de habitantes da freguesia de Morretes que possuíam a habilidade de preparar medicamentos. Em junho de 1840, por exemplo, ele empregou no tratamento de Maria Ferreira remédios preparados por um alfaiate. Por meio da leitura do excerto transcrito a seguir, verifica-se a permanência, no tratamento de Ferreira, das técnicas de limpeza intestinal:

9 [de junho de 1840]. Terça de manhã inda tomou huns remedios q' fes Joaq ${ }^{m}$ Joze Per ${ }^{a}$ alfaiate. Depois do meio dia lhe sobrevierão huas dores fortissimas nas cadeiras, e tambem por todo o ventre, que julgo ser as ventozidades encalhadas nos intestinos, e se lhe poz o emplasto antehysterico. De noite parece pasou melhor aliviando as $m^{\text {mas }}$ dores.

10. Quarta fra de tarde, voltou outra ves as dores nas cadeiras e ventre, e tendo a via do anus algum tanto inflammada sem poder evacuar o q' só fazia a poder de clysteis e com bastante fastio.

11. Quinta de manhã tomou hum purgante laxativo (q' não se obrou) pasou quazi sem as dores de cadeiras e ventre, porem $m^{\text {to }}$ fraca e abatida.

12. Sesta principiou de manhã com anciam ${ }^{\text {to }}$ do estomago $p^{r}$ se achar empatada em razão de não poder obrar e ter a via inflammada tomou clysteis de manhã o elixir e o $\mathrm{m}^{\text {mo }}$ a tarde e tambem a Genebra com a gomarabia. ${ }^{40}$

A despeito da solicitação dos préstimos de indivíduos que produziam remédios caseiros, Vieira dos Santos continuou a encaminhar cartas para Guilherme Wylie. Em face da ausência de médicos na freguesia de Morretes, Vieira os Santos adotou a prática de relatar para Wylie, em missivas, o estado de saúde de sua esposa. Nessas

\footnotetext{
${ }^{40}$ SANTOS, Memórias dos sucessos..., p. 376. 
cartas, o comerciante português solicitava ao médico a indicação de remédios e procedimentos adequados para aplacar os padecimentos de Maria Ferreira. No fim de agosto de 1840, a enferma estava a sofrer de incômodos cardíacos e estomacais. Diante desse cenário adverso, Vieira dos Santos procurou a orientação de Wylie:

Sabado pasou todo o dia té a noite $\mathrm{m}^{\text {to }}$ encommodada e foi attacada da mais violenta cardialgia, $m^{\text {to }}$ ansiada do estomago, com arrotos fortissimos de estampido, com o q' levou desde as ave-marias te da meia noite, em que descansou algum tanto. Dormio hum bocado, acordandose de madrugada com dores do estomago. N.B. = A este tempo teve desconfiansas que a molestia tinha pasado, a huma inflammação do estomago $p^{a}$ cujo fim consultei ao medico o Dr. Guilherme Wylie em carta de 30 de Agosto pedindo-lhe remedios $p^{a}$ as affecçõens seg ${ }^{e s} 1^{a}$ fasto rigoroso $-2^{a}$ debilidade permanente $-3^{a}$ ventozidades $-4^{a}$ cardialgia $-5^{a}$ adstrição de ventre $-6^{a}$ dor periodica de cadeiras e ventre $-7^{a}$ corrim $^{\text {to }}$ de flores brancas. $^{41}$

As informações presentes no Quadro da vida e morte de Maria Ferreira possibilitam o conhecimento acerca das altercações familiares diante do insucesso do tratamento caseiro ministrado por Vieira dos Santos com o auxílio ocasional de curandeiros. Essas circunstanciais contendas eram decorrentes da ausência de novas perspectivas para o tratamento. Assim, restava àquele comerciante executar procedimentos marcados pelo emprego de remédios caseiros que aliviavam temporariamente as dores de Maria Ferreira.

Nesse quadro, as reclamações da enferma impeliram Vieira dos Santos a recorrer ao auxílio do curandeiro Julião. Assim, as informações apresentadas na sequência demonstram que na primeira quinzena de setembro de 1840 não houve melhora no estado de saúde de Maria Ferreira, apesar do emprego dos remédios preparados pelo referido curandeiro. De outra parte, o excerto transcrito a seguir permite salientar o aspecto pouco disciplinado do tratamento caseiro da mencionada enferma. Esse aspecto decorre do fato de que, em algumas ocasiões, Maria Ferreira optava por não consumir os medicamentos:

6 [de setembro de 1840]. Domingo; de dia pasou algua coiza melhor; mas de noite lhe vierão os arrotos, e flatos. Dormio mais algum tanto.

7. Segunda tomou huns remedios feitos $p^{r}$ Julião e levou todo o dia só dando arrotos. De noite gr de cardialgia q' levou ate as 10 ou 11 horas. Depois sempre dormio algua coiza.

8. Terça - 9 Quarta - 10 Quinta e 11 Sesta pasou em todos estes dias, ora aliviada, e ora com flatos e dores das quaes não se fes notta especificada.

${ }^{41}$ SANTOS, Memórias dos sucessos..., p. 384. 
9. Sabado de manhã tomou o $\mathrm{pr}^{\circ}$ purgante de oleo de ricinio com o qual parece obrou. De tarde ate de noite com dores de cadeiras, arrotos

10. Domingo tomou o $2^{\circ}$ purgante de óleo de ricinio obrou bastante, mas levou todo o dia $m^{\text {to }}$ anciada com o estomago, ventre e dores de cadeiras, e $^{\text {to }}$ abatida e dezanimada todo o dia te perto das 10 horas noite, depois sempre dormio.

11. Segunda não tomou nenhuns purgantes e pasou o dia regularmente, mas de noite esteve $m^{\text {to }}$ dezanimada com o corpo bastante cahido de forsas. ${ }^{42}$

Em outubro de 1840, um mês antes do falecimento de Maria Ferreira, Vieira dos Santos continuava a demandar de habitantes da freguesia de Morretes a preparação de remédios para o tratamento da esposa. Em geral, esses remédios eram destinados à realização de limpeza intestinal e estomacal. João Silveira de Mendonça foi um dos indivíduos a quem Vieira dos Santos recorreu para a produção desses remédios. Porém, a ingestão desses produtos não teve efeitos benéficos. No segundo semestre do mencionado ano, o estado de saúde de Maria Ferreira continuou a se agravar. No fim de outubro, esse agravamento impossibilitou-a de se locomover. Ela permaneceu em tal situação até o dia do falecimento, em 13 de novembro:

8 [de outubro de 1840]. Quinta de manhã tomou hum vomitorio de De mistura salina composto $p^{r}$ João Silveira de Mendonça com o qual pouco obrou, mas levou toda a tarde e parte da noite encommodada do estomago com amargor $e$ ventozidades.

10. Sabado pasou toda a tarde $m^{\text {to }}$ encommodada com as ventozidades do estomago e cardialgia $p^{r}$ cauza de ter bebido hum bocado de vinho, e levou a gemer.

11. Domingo levou desde manhã té o meio dia encommodada com cardialgia e ancia no estomago talves $\mathrm{pr}$ q' tivese comido hum mingao de farinha de trigo, tendo vomitar, parecendo ser indigestão, e levou a gemer té hua hora da tarde.

12. Segunda de manhã tomou segundo vomitorio de mistura salina, com o qual pouco obrou, mas levou sem cesar a gemer toda a tarde ate as 10 ou 11 horas da noite com $m^{\text {tas }}$ anciedades do estomago sem poder obrar $p^{a}$ baixo, com dores no ventre e cadeiras, finalmente $m^{\text {to }}$ dezanimada, dizendo-me que desde o dia 8 ate já tinha os pés e coxas inchadas.

14. Quarta de manhã tomou o purgante de oleo de ricinio, com o qual obrou alguas vezes, e desde então ficou de tal modo abatida de forsas que nunca mais se pode levantar

\footnotetext{
${ }^{42}$ SANTOS, Memórias dos sucessos..., p. 385.

SAECUlUM - ReVISTA DE História [36]; João Pessoa, jan./jun. 2017.
} 
sozinha, e nem se por de pé. Esteve de manhã com o excesso de obrar, tão triste, dezanimada e ate com o rosto triste, pálido, e cadaverico. ${ }^{43}$

Nesse contexto, Vieira dos Santos fez nova tentativa para obter orientações de Guilherme Wylie. Entretanto, esse médico não respondeu a missiva enviada por aquele comerciante. Por consequência, Vieira dos Santos solicitou por carta que um boticário, Joaquim Pires Gracia, fornecesse a ele orientações para a continuidade do tratamento de Maria Ferreira. Ao mesmo tempo, ele, Vieira dos Santos, buscava o auxílio de outros indivíduos que dominavam conhecimentos de preparação de remédios, tais como Aninha da Costa.

Dessa forma, as informações respeitantes aos últimos meses do tratamento de Maria Ferreira evidenciam que, em sociedades desprovidas de médicos, os familiares dos enfermos providenciavam um eclético tratamento de saúde. Esse ecletismo consistia no acatamento das múltiplas sugestões terapêuticas fornecidas por pessoas que conheciam as artes populares de cura.

Em suma, esse ecletismo era decorrente do fato de que a terapêutica agregava recomendações de curandeiros, boticários, e também informações adquiridas em manuais de medicina. Ao mesmo tempo, eram empregadas as orientações realizadas de forma eventual por médicos de vilas adjacentes. Leia-se, pois, o excerto memorialístico no qual Vieira dos Santos informa que, em outubro de 1840, recorreu aos préstimos de um boticário e de uma mulher que dominava o conhecimento da preparação caseira de remédios:

Sabado esteve todo o dia quazi sem gemer, mas sempre com o estomago a modo de cheio, parece $q^{\prime} p^{r}$ beber huns remedios feitos $p^{r}$ Aninha da Costa q' lhe fes ancias $m^{\text {to }} o$ estomago e ventre, e levou gemendo desde as Ave Marias té alta noite. N.B. = Como o medico não desse resposta a $\mathrm{m}^{a}$ carta q' lhe escrevi em 22 de $7^{\text {bro }}$ escrevi hua carta ao Boticario Joaq ${ }^{m}$ Pires Gracia em 24 de $8^{\text {bro }}$ consultando-o. ${ }^{44}$

Conforme destacado, Maria Ferreira de Oliveira faleceu no dia 13 de novembro de 1840, em sua residência, na freguesia de Morretes. A maior parte de seu tratamento foi realizada mediante o emprego de recomendações de indivíduos que não possuíam a formação na medicina erudita. A busca pelas orientações médicas, na família de Ferreira, não impedia a concessão de autoridade às sugestões de boticários, curandeiros, escravos e de outros indivíduos que manifestassem aptidão para o preparo de medicamentos.

Todavia, existiam obstáculos para o contato frequente com médicos. Diante desses obstáculos, coube ao esposo de Maria Ferreira estabelecer contato com indivíduos que dominavam técnicas populares de cura. Em síntese, essas técnicas eram empregadas para a limpeza do organismo e abrandamento de dores. Vieira dos

\footnotetext{
${ }^{43}$ SANTOS, Memórias dos sucessos..., p. 388-390.

${ }^{44}$ SANTOS, Memórias dos sucessos..., p. 392.
} 
Santos, portanto, ministrou um tratamento de caráter paliativo, no qual a cessação momentânea das dores era o limite do efeito dos remédios e procedimentos utilizados.

\section{Considerações Finais}

O Quadro da vida e morte de Maria Ferreira de Oliveira, redigido por Antônio Vieira dos Santos, comporta informações que permitem o reconhecimento das dificuldades enfrentadas pelos habitantes de uma sociedade do extremo sul da Província de São Paulo quanto ao tratamento de enfermidades. A escassez de médicos, por exemplo, era uma das principais dificuldades. Nesse contexto, constatase que as orientações médicas eram almejadas pelos habitantes daquela pequena sociedade provincial. Porém, a esses habitantes era possível apenas manter contato com os médicos por meio de correspondência epistolar.

Em virtude das adversidades, restava aos moradores das pequenas sociedades recorrerem aos serviços de indivíduos que atuavam como curandeiros e boticários. No princípio do século XIX, no contexto da freguesia de Morretes, os saberes populares de cura preservavam a sua legitimidade. Esses saberes eram requisitados por membros da elite social.

O caso do tratamento das enfermidades de Maria Ferreira de Oliveira evidencia que, na referida região, indivíduos pertencentes à elite local ambicionavam manter contato com os profissionais formados na medicina erudita. Para tanto, eles viajavam para municípios vizinhos com o objetivo de receber o auxílio dos médicos. Contudo, não havia condições de essas viagens serem realizadas de forma rotineira. Assim, a comunicação por carta era uma alternativa factível. Nesse contexto, a comunicação epistolar entre o médico e o familiar do enfermo ocorria de maneira ocasional.

Em decorrência desses reveses, recorria-se aos conhecimentos de boticários $e$ curandeiros, os quais eram demandados a produzir remédios. Ao mesmo tempo, o tratamento de saúde em uma sociedade carente de assistência médica assumia um caráter caseiro. Por meio do estudo do caso de Maria Ferreira, verifica-se que os familiares eram impelidos a improvisar uma terapêutica destinada apenas a aplacar dores crônicas. Nesse quadro, o conhecimento obtido em manuais de medicina popular era funcional para a elaboração de uma terapêutica caseira. Portanto, a ausência de assistência médica naquela freguesia afetava os ocupantes de posições superiores na hierarquia social.

Em síntese, a família de Maria Ferreira não se eximia de manter contato, por exemplo, com curandeiros e escravos que se mostrassem dispostos a produzir remédios. Assim, recorrer às formas populares de cura era uma medida encarada como indispensável pelo esposo da enferma. As orientações dos curandeiros eram aglutinadas com as orientações fornecidas pelos profissionais formados no saber da medicina oficial. Desse modo, a precariedade da assistência médica instaurava uma situação na qual esse comerciante de origem portuguesa promoveu o emprego tanto das recomendações ocasionais dos médicos quanto das orientações obtidas rotineiramente junto aos curandeiros e leigos que dominavam informações sobre procedimentos terapêuticos. 
Dessa forma, o agravamento de uma enfermidade e a dificuldade de acesso a médicos eram situações que geravam a aproximação dos moradores das pequenas sociedades com os curandeiros. Por conseguinte, os textos de reminiscências de Vieira dos Santos contêm indícios de que, em uma pequena sociedade do litoral paulista, no princípio do século XIX, os familiares dos doentes, na execução de uma terapêutica, aliavam as recomendações de médicos às sugestões e remédios produzidos por curandeiros e boticários.

As artes populares de cura dominadas por escravos também influíam no tratamento de membros da elite local de Morretes. Nesse âmbito, as aludidas deficiências da assistência médica, no contexto de uma sociedade interiorana do Império, levavam os integrantes da elite local a manterem frequentes contatos com os componentes de estratos mais inferiorizados na hierarquia social.

\section{$\operatorname{soc} 2$}

\section{RESUMO}

Neste artigo é desenvolvido um estudo acerca do tratamento das enfermidades de Maria Ferreira de Oliveira (1787-1840), nos anos de 1839 e 1840. Orientado por um médico local e também por curandeiros, o tratamento foi executado pelo marido de Maria Ferreira, o comerciante português Antônio Vieira dos Santos (1784-1854). O referido casal residia na freguesia de Morretes, que pertencia à vila de Antonina. Essa vila estava sob a jurisdição da Província de São Paulo. Nesse quadro, o presente artigo consiste na produção de um conhecimento sobre formas de tratamento de doenças desenvolvidas em uma área do interior de província do Brasil Meridional. Assim, compete evidenciar as formas pelas quais um componente da elite de pequena social provincial procedeu ao tratamento das enfermidades de seu cônjuge. Cabe ressaltar, assim, a natureza $e$ os efeitos desse tratamento, o qual era essencialmente caseiro. Sustenta-se o argumento de que os familiares da enferma desenvolveram um tratamento eclético, marcado pela busca do auxilio de médicos e curandeiros, $e$ também pela utilização de manuais de medicina popular. Nesse âmbito, o estudo empreendido neste artigo comporta evidências sobre a ativação de interação membros de elites locais e integrantes de estratos mais subalternos da hierarquia social de uma freguesia provincial no âmbito da preparação de formas populares de tratamento de saúde.

Palavras Chave: Hierarquias Sociais; Práticas Curativas; Sociedade Provincial; Medicina Popular.

\section{ABSTRACT}

This paper does a study on the treatment of the diseases of Maria Ferreira de Oliveira (1787-1840) in 1839 and 1840. Guided by a physician and also by healers, the treatment was done by Maria Ferreira's husband, the Portuguese merchant Antônio Vieira dos Santos (1784-1854). The couple lives in the Morretes parish, that belonged to Antonina village. This hamlet was under the jurisdiction of São Paulo Province. In this context, this article consists of the production of a knowledge about the forms of treatment of diseases developed in an area of the Southern Brazilian inland countryside. Thus, it is important to highlight the ways in which a prominent man of the small provincial social elite proceeded to treat the illnesses of his wife. It is worth mentioning the nature and effects of this treatment, which was essentially home-brewed. The paper argues that the patient's relatives developed an eclectic treatment, pointed by the search of the help of physicians and healers, and also by the use of popular medicine manuals. In this context, This case brings some evidences on the interaction of local elites members and more subordinate strata of the social hierarchy of a provincial parish in the context of the preparation of popular forms of health treatment.

Keywords: Social Hierarchies; Healing Practices; Provincial Society; Popular Medicine. 